\title{
Oxidative stress development in the leaves of Amaranthus cruentus L. containing amaranthine under conditions of nighttime low temperatures, soil hypoxia and the combined effects of both stress factors
}

\author{
Tamara Balakhnina ${ }^{1 *}$, Murat Gins ${ }^{2}$, and Irina Fomina ${ }^{1,3}$ \\ ${ }^{1}$ Institute of Basic Biological Problems, Russian Academy of Sciences, Pushchino, Moscow Area, 142290, Russia \\ ${ }^{2}$ Federal Research Centre for Vegetable Growing, Moscow Area, 143072, Russia \\ ${ }^{3}$ Biosphere Systems International Foundation, Tucson, Arizona, 85755, USA
}

Received February 7, 2019; accepted July 8, 2019

\begin{abstract}
A b s t r a c t. The investigation of the effect of night chilling up to $4 \pm 2^{\circ} \mathrm{C}$, soil flooding at the optimal day and night temperature, and the combined effect of these stress factors on the adaptive potential of Amaranthus cruentus L. $c v$ "Krepysh" containing amaranthine showed that changes in the intensity of the peroxide oxidation of lipids and superoxide dismutase activity, varied in antiphase to each other, both in the control and in experimental plants. Due to night chilling, unlike hypoxia, the content of amaranthine decreased shaply at the beginning of the stress period and then increased and significantly exceeded the control level until the end of the experiment. It has been suggested that lowering the temperature induces amaranthine synthesis, whereas with the development of hypoxic stress due to the reactions of reactive oxygen species neutralization, constitutive amaranthine is used. The suppression of plant growth during periods of hypothermia was more pronounced than it was due to soil hypoxia, this phenomenon may be associated with a decrease in the overall level of metabolism under conditions of hypothermia and is another example of the adaptive reactions of plants. It was found that the negative effects of the combined activity of soil hypothermia and soil hypoxia on plants, were greater than the negative effects of each stressor applied separately.

K e y w o r d s: Amaranthus cruentus L., night hypothermia, oxidative stress, peroxide processes, soil flooding
\end{abstract}

\section{INTRODUCTION}

Soil flooding, a decrease in temperature at night, as well as a combination of both, often occur in the spring, adversely affecting the growth and development of plants, hence they are factors that inhibit the development of crop production. The main reason for the disruption of physio-

*Corresponding author e-mail: tbalakhnina@rambler.ru logical functions, and the damage and death of heat-loving plants at lower temperatures is a decrease in the amount of polyunsaturated fatty acids in the cell membranes (Lukatkin and Golovanova,1988). One nonspecific reaction of plants to the activity of stress factors inducing hypoxia is the formation of an excessive amount of reactive oxygen species (ROS), which can cause the oxidative destruction of photosystems, pigments, proteins and membrane lipids. The peroxide oxidation of lipids (POL) leads to a decrease in the content of polyunsaturated fatty acids in cell membranes (Arbona et al., 2008; Balakhnina et al., 2009, 2010). Hypoxia, as well as lower temperatures, is an inducer of oxidative stress. The activation of lipid peroxidation during hypoxia is associated with the initiation of the formation of an excessive amount of reactive oxygen species, primarily with superoxide $\left(\mathrm{O}_{2}^{-} \cdot\right)$ formation. One of the sources of superoxide radicals are the electron transfer chains in chloroplasts, mitochondria and microsomes (Asada, 2006). Under the conditions of hypoxia, the process of electron leakage from the restored carriers of electron transport chains to oxygen is intensified with the formation of its radical forms. In addition, there are a number of other processes leading to the formation of reactive oxygen species. The activity of NADH oxidase, which forms superoxide anion radicals in the presence of $\mathrm{O}_{2}$ during the oxidation of NADH (Arbona et al., 2008), increases. The cleavage of ATP leads to the formation of xanthine, which is oxidized by xanthine oxidase, which also causes the formation of

(C) 2019 Institute of Agrophysics, Polish Academy of Sciences 
superoxide radicals. The latter, spontaneously or under the influence of superoxide dismutase (SOD), $\mathrm{O}_{2}^{-} \cdot$ radicals converted into a less toxic, but longer-lived product - hydrogen peroxide $\left(\mathrm{H}_{2} \mathrm{O}_{2}\right)$. Peroxide is decomposed by catalase and peroxidases to $\mathrm{H}_{2} \mathrm{O}$ and $\mathrm{O}_{2}$ (Asada, 2006).

Previously, using the examples of corn and peas (Bennicelli et al., 1998), barley (Balakhnina et al., 2009), beans (Balakhnina et al., 2010) and rape (Balakhnina et al., 2012) we have shown that soil flooding induces oxidative stress both in plant roots which are in the zone of the acting factor, and in the leaves, which experience an indirect effect of the stressor. The physiological and biochemical reactions of damage and adaptation of the studied plants depended on both the dose of the acting stress factor and the evolutionally formed resistance of these crops to soil flooding and oxygen deficiency in the root zone (Balakhnina et al., 2009; $2010 ; 2012)$. The ability of plants to withstand the stresses and the aftereffect of soil hypoxia is directly dependent on the activity of enzymes that detoxify ROS such as superoxide dismutase (SOD), catalase, glutathione reductase (GR), guaiacol peroxidase (GPX) and ascorbate peroxidase (AsP) (Balakhnina et al., 2009; 2010; 2012).

Amaranthine is an important class of water-soluble red-violet pigment belonging to the category of betalain pigments, which are characteristic of plants of the order Amaranthus and Caryophyllales. Amaranthine was found in the red roots, stems and leaves of some plants (Phebe et al., 2009; Shao et al., 2009; Gins et al., 2016). It was shown that amaranthine can effectively detoxify ROS to relieve oxidative stress and that it plays an important role in photoprotection (Xiong-Wei Chen et al., 2013). This compound increased plant resistance to the effect of UV-A radiation (Gins et al., 1997), and higher temperatures (Shao et al., 2009). It was also shown that amaranthine containing plants are more tolerant to the development of oxidative stress induced by salt, than wheat plants (Gambarova and Gins, 2008). The total antioxidant activity in $1 \mathrm{~g}$ of dry leaf powder of amaranthine containing Amaranthus tricolor was equivalent to $0.035 \mathrm{~g} \mathrm{ml}^{-1}$ of ascorbic acid (Clemente and Desai, 2011). Vegetable plants are the most affordable source of essential antioxidant metabolites, the lack of which leads to a sharp decrease in resistance to environmental stresses. Amaranth (Amaranthus tricolor L.) is a promising food and medicinal plant (Gins et al., 2017).
The goal of this work was to investigate the reactions of plant adaptation and oxidative damage of the amaranthine containing, heat-tolerant Amaranthus cruentus L. cv. "Krepysh" to hypothermia, soil hypoxia and the combined activities of these stress factors. According to our previous studies (Gins et al., 1997; Gambarova and Gins, 2008), this cultivar tolerates drought more readily than soil flooding; and the amaranthine pigment has an antioxidant activity directed to the suppression of superoxide-anion radicals.

\section{MATERIALS AND METHODS}

Amaranthus cruentus L. cv. "Krepysh" seeds after germination were grown in $1 \mathrm{dm}^{3}$ plastic pots filled with soil taken from the arable layer of grain-fallow crop rotation after winter wheat (leached chernozem, medium thick, medium humus, heavy clayey) of a cultivated field in the Penza region, Russia. The soil characteristics obtained by the methods described in (Amelyanchik et al., 2001) showed that the soil was slightly acidic, had a low content of available nitrogen, a medium content of phosphorus and an elevated content of potassium (Table 1).

Before the experiment, soil material from the field was dried until it reached a stable mass in order to test the water content. The pots (48 in total) with seedlings were placed into growth chambers, weighed every day and watered until a level of $20 \pm 5 \%$ soil moisture was achieved. The air temperature was maintained at $24 \pm 2^{\circ} \mathrm{C}$ during the day and $20 \pm 2^{\circ} \mathrm{C}$ at night. The photoperiod was $12 / 12 \mathrm{~h}$ and the light intensity was set at $250 \mu \mathrm{mol}$ photons $\mathrm{m}^{-2} \mathrm{~s}^{-1}$. As a light source light-emitting diode (LED) lamps "AtomSvet BIO" were used. Relative air humidity was $45 \pm 5$ in the day and $70 \pm 5 \%$ at night. After 21 days of growth under optimal conditions, the seedlings were divided into four treatments in three replicates:

1. control (C) $-24 \pm 2^{\circ} \mathrm{C}$ during the day and $20 \pm 2^{\circ} \mathrm{C}$ at night, with optimal soil watering;

2. flooding ( $\mathrm{Fl})-24 \pm 2^{\circ} \mathrm{C}$ during the day and $20 \pm 2^{\circ} \mathrm{C}$ at night, with complete soil flooding (up to a level of $1 \mathrm{~cm}$ under the soil surface);

3. night chilling (Chil) $-24 \pm 2^{\circ} \mathrm{C}$ during the day and 4 $\pm 2^{\circ} \mathrm{C}$ at night, with optimal soil watering.

4. night chilling and flooding (Chil+Fl) $-24 \pm 2^{\circ} \mathrm{C}$ during the day and $4 \pm 2^{\circ} \mathrm{C}$ at night, with complete soil flooding; up to $1 \mathrm{~cm}$ below the soil surface.

Table 1. Content of humus, mobile forms of nitrogen $(\mathrm{N})$, phosphorus $(\mathrm{P})$ and potassium $(\mathrm{K})$ in the soil, soil moisture and $\mathrm{pH}(\mathrm{meth}-$ ods of determination shown in brackets was described by Amelyanchik et.al., 2001)

\begin{tabular}{|c|c|c|c|c|c|c|}
\hline $\begin{array}{c}\text { Humus } \\
\text { (Tyurin's method) }\end{array}$ & $\begin{array}{c}\mathrm{N} \\
\text { (Cornfield's } \\
\text { method) }\end{array}$ & $\begin{array}{c}\mathrm{P} \\
\text { Chirikov's method }\end{array}$ & $\frac{\mathrm{K}}{\text { Chirikov's method }}$ & $\begin{array}{c}\text { Soil moisture } \\
\% \mathrm{w} / \mathrm{w}\end{array}$ & $\mathrm{pH}$ in $\mathrm{KCl}$ & $\mathrm{pH}$ in $\mathrm{H}_{2} \mathrm{O}$ \\
\hline$\%$ & & $\mathrm{mg} \mathrm{kg}^{-1}$ of soil & & & & \\
\hline $5.17 \pm 0.03$ & $106 \pm 11$ & $80 \pm 12$ & $117 \pm 18$ & $20 \pm 5$ & $5.1 \pm 0.02$ & $6.9 \pm 0.03$ \\
\hline
\end{tabular}


Soil and plant measurements were performed after 0,1 , 3,7 and 9 days of the differentiation of soil and temperature conditions.

In order to estimate the adaptive capacity of the plants, the intensity of the oxidative processes was evaluated by measuring the content of thiobarbituric acid reactive substances (TBARs), and the plant antioxidant potential was examined by measuring the superoxide dismutase activity (SOD), as well as the concentration of amaranthine and photosynthetic pigments in the leaves. The analyses were performed using crude homogenates and enzyme extracts from the leaves of the control and treatment plants. All the results were presented in the form of per one gram of leaf dry mass. Leaf samples were dried at $95^{\circ} \mathrm{C}$ until the stabilization of the dry mass was attained.

The middle parts of fully developed leaves without the midrib $(0.5 \mathrm{~g})$ were homogenized manually in a mortar with $4.5 \mathrm{ml}$ of cooled $\left(2-4^{\circ} \mathrm{C}\right) 30-\mathrm{mmol} \mathrm{K} / \mathrm{Na}$ phosphate buffer, pH 7.4, containing $0.1 \mathrm{mM}$ EDTA and $2 \%$ PVP. The homogenates were filtered through a nylon cloth. A part of the filtrate defined by the research team as crude homogenate was used for the assessment of the intensity of the peroxidation process on the basis of TBARs concentration. The second part of the filtrate was centrifuged at $15000 \mathrm{~g}$ for $20 \mathrm{~min}$ and supernatant, which was described as the enzymatic extract, was used for determination of the SOD activity.

The intensity of the POL processes was assessed by the content of products reacting with thiobarbituric acid (TBARs) using the method of (Uchiyama and Mihara, 1978). The TBARs concentration was calculated taking into account an extinction coefficient of $1.56 \times 10^{-5} \mathrm{M} \mathrm{cm}^{-1}$.

The SOD activity, was determined using the method of (Giannopolitis and Ries, 1977) on the photoreduction of p-nitrotetrazolium blue (NBT) (Mm 817.68) in the presence of riboflavin and methionine, thereby generating superoxide anion radicals $\left(\mathrm{O}_{2}{ }^{-}\right)$. NBT is reduced to a blue formazan with a maximum absorption at $560 \mathrm{~nm}$. A unit of SOD activity was assumed to indicate a $50 \%$ inhibition of NBT reduction.

The Amaranthine content was determined spectrophotometrically as described in Stintzing et al. (2002) with a slight modification. Fresh leaves $(0.05 \mathrm{~g} \mathrm{FW})$ were ground with a mortar and pestle with $10 \mathrm{ml}$ ethanol for $30 \mathrm{~min}$ followed by centrifugation at $8000 \mathrm{~g}$ for $10 \mathrm{~min}$ at $4^{\circ} \mathrm{C}$, then the supernatant was discarded. The process was repeated twice. The precipitation was soaked in $5 \mathrm{ml}$ of distilled $\mathrm{H}_{2} \mathrm{O}$ for $30 \mathrm{~min}$, and then centrifuged at $8000 \mathrm{~g}$ for $10 \mathrm{~min}$ at $4^{\circ} \mathrm{C}$. The supernatant absorbance was measured spectrophotometrically at a wavelength of $537 \mathrm{~nm}$, with a spectrophotometer (Hitachi 557, Japan) and the amaranthine content was calculated on a per gram dry mass (DM) basis.

The content of the photosynthetic pigments was determined spectrophotometrically in $80 \%$ acetone, Lichtenthaler and Wellburn(1985) formulas were used for the calculations.
The analyses were made in several replications, the details of which are noted in the figure captions; the means and standard deviations were calculated. A one-way ANOVA was used to test the significance for differences between means at $\mathrm{p}<0.05$.

\section{RESULTS AND DISCUSSION}

Under the influence of soil hypoxia, a decrease in nighttime temperatures, and with the combined activities of these stress factors, the intensification of POL processes at 200,170 and $220 \%$, respectively, relative to the control plants (Fig. 1) was observed after three days of the experiment. Then, on the 7th day of the experiment, the content of TBARs in the leaves of the flooded plants, both those maintained at the optimum temperature and those subjected to nighttime hypothermia, decreased to 150 and $130 \%$ respectively, relative to the control plants. When exposed to night hypothermia against the background of optimal soil moisture, the intensity of POL was maintained at $170 \%$ of the control. By the end of the experiment, on the 9th day, there were no significant differences between the experimental and the control plants (Fig. 1).

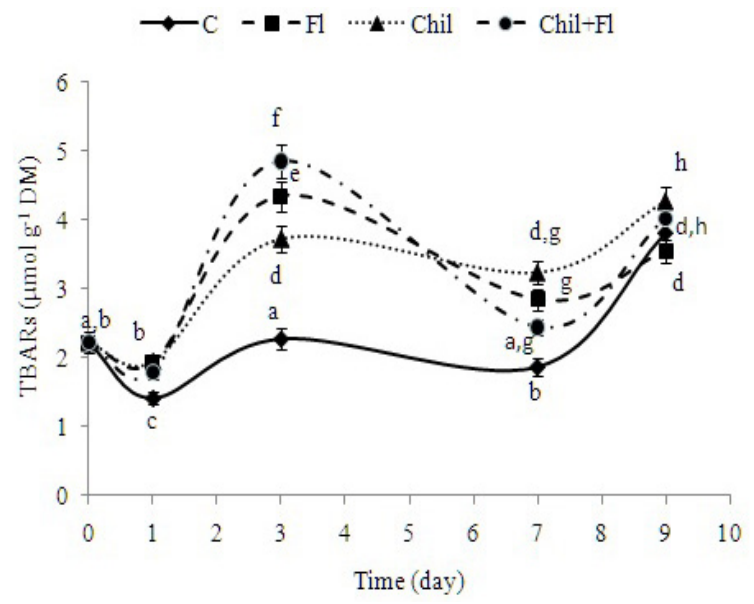

Fig. 1. Content of thiobarbituric acid reactive substances (TBARs) in leaves of amaranth "Krepysh" grown under control conditions (C), night chilling up to $4 \pm 2^{\circ} \mathrm{C}$ (Chil), soil flooding (Fl), as well as under combined effect of soil hypoxia and night chilling (Chil+ Fl). Bars indicate standard deviation $(n=5)$. Different letters means significant difference between means at $p<0.05$. Day zero correspond to the time of introduction of the stress.

After a day of exposure to soil hypoxia, the activity of SOD in the leaves exceeded the activity of the control plants by $28 \%$ (Fig. 2). In the conditions of night hypothermia, both with optimal moistening of the substrate and during flooding, differences between the variants were not observed. On the third day of the experiment, SOD activity in the leaves of all the experimental variants decreased significantly and amounted to $50-70 \%$ of the activity of the control plants (Fig. 2). However, on the 7th day of the experiment, an increase in the SOD activity was observed 


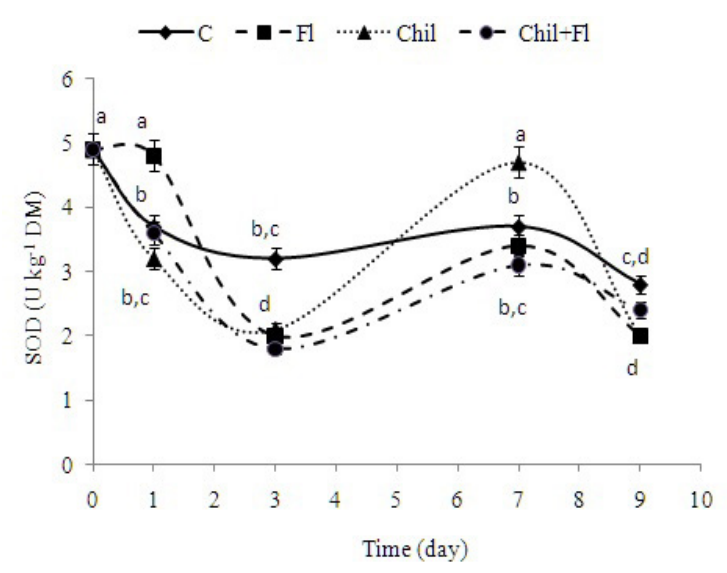

Fig. 2. Superoxide dismutase activity (SOD) in leaves of amaranth "Krepysh" grown under control conditions (C), night chilling up to $4 \pm 2^{\circ} \mathrm{C}(\mathrm{Chl})$, soil flooding $(\mathrm{Fl})$, as well as under combined effect of soil hypoxia and night chilling $(\mathrm{Chil}+\mathrm{Fl})$. Bars indicate standard deviation $(\mathrm{n}=5)$. Other explanations as in Fig. 1.

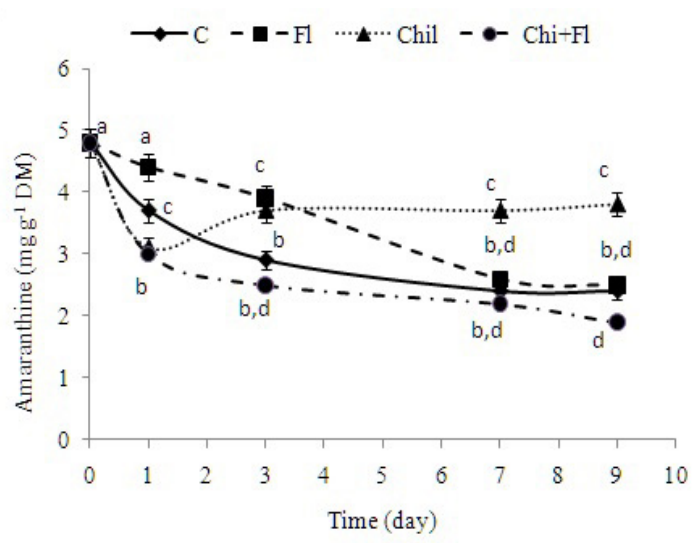

Fig. 3. Amaranthine concentration in leaves of amaranth "Krepysh" grown under control conditions (C), night chilling up to $4 \pm 2^{\circ} \mathrm{C}(\mathrm{Chl})$, soil flooding $(\mathrm{Fl})$, as well as under combined effect of soil hypoxia and night chilling $(\mathrm{Chil}+\mathrm{Fl})$. Bars indicate standard deviation $(\mathrm{n}=7)$. Other explanations as in Fig. 1.

in all experimental plants, and the level of this parameter exceeded the activity of the control plants by $26 \%$ in samples subjected to night hypothermia with optimal soil moisture. In other variants, the activity of the enzyme in the experimental plants was practically identical with the control ones (Fig. 2). By the end of the experiment, there were no significant differences in SOD activity between the leaves of the control and all experimental samples (Fig. 2).

Under the conditions of this experiment, the content of amaranthine in the leaves of the control plants decreased from 4.8 to $2.4 \mathrm{mg} \mathrm{g}^{-1}$ dry weight, a fall of almost $50 \%$ (Fig. 3). A significant decrease in the concentration of amaranthine was also observed in the leaves of experimental plants grown under conditions of soil hypoxia and during night hypothermia in combination with soil flooding,

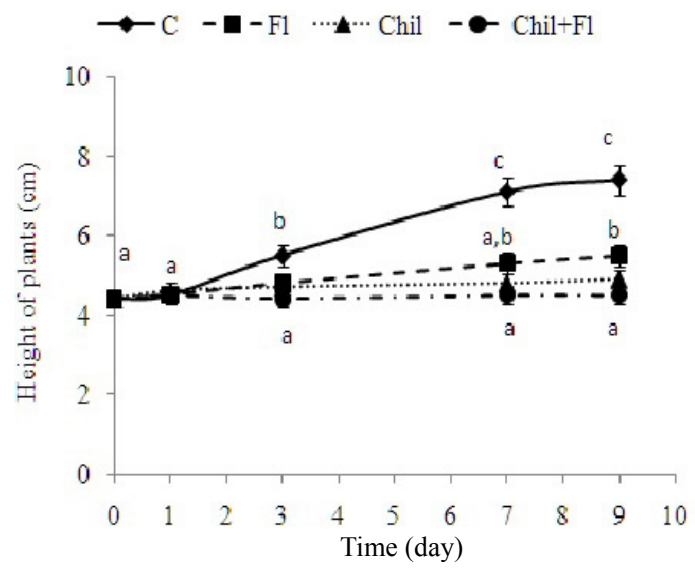

Fig. 4. Height of amaranth "Krepysh" shoots grown at control conditions (C), the night chilling up to $4 \pm 2^{\circ} \mathrm{C}$ (Chil), soil flooding (Fl), as well as under combined effect of soil hypoxia and night chilling (Chil+Fl). Bars indicate standard deviation $(\mathrm{n}=25)$. Other explanations as in Fig. 1.

which on the 9th day of the experiment was 50 and $60 \%$, respectively, relative to the initial values (Fig. 3). At the same time, the concentration of pigment in the leaves of the flooded plants at the early stage of hypoxic stress decreased more slowly and during the first 3-4 days amaranthine concentration was significantly (28\%) higher than in the control plants. This may be due to the strengthening of the adaptation potential through an increase in the SOD activity (Fig. 2). Then the pigment content of the flooded plants was reduced. A similar picture was observed when studying the effect of UV-A radiation on the adaptive potential of amaranth plants. It was found that the concentration of amaranthine increased at an early stage and then sharply decreased with the further development of photoinduced stress (Gins et al., 1997).

Another result was observed in plants under night hypothermia conditions with optimal soil moisture. A sharp drop in the concentration of amaranthine in the leaves was replaced by an increase in the pigment content by $58 \%$ relative to the control plants, and the elevated level was maintained until the end of the experiment (Fig. 3). In the opinion of the authors these results may indicate that the cold induces the synthesis of amaranthine. Under conditions of soil flooding, as in the case of UV-A radiation (Gins et al., 1997), the amaranthine content decreased due to its active use in the quenching reaction of superoxide anion radicals during the development of stress.

The concentrations of $\mathrm{Chl}(\mathrm{a}+\mathrm{b})$ in the leaves of the control plants decreased one day after the start of the experiment, but later stabilized and remained at approximately the same level for the next 7 days (Fig. 4). With the activities of (Fl), (Chil) and (Chil+Fl) stressors, a steady decrease in pigment concentration was observed during the whole 


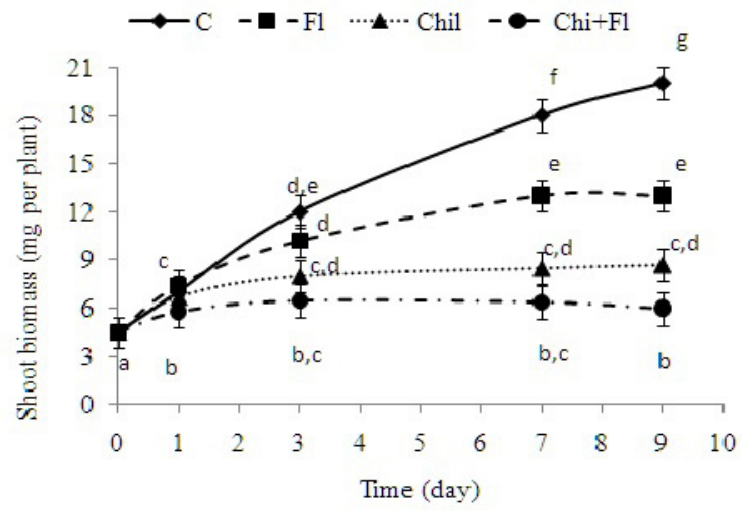

Fig. 5. Biomass of amaranth "Krepysh" plants grown under control conditions $(\mathrm{C})$, the night chilling up to $4 \pm 2^{\circ} \mathrm{C}(\mathrm{Chl})$, soil flooding $(\mathrm{Fl})$, as well as under combined effect of soil hypoxia and night chilling $(\mathrm{Chil}+\mathrm{Fl})$. Bars indicate standard deviation $(\mathrm{n}=$ $25)$. Bars indicate standard deviation $(n=7)$. Other explanations as in Fig. 1.

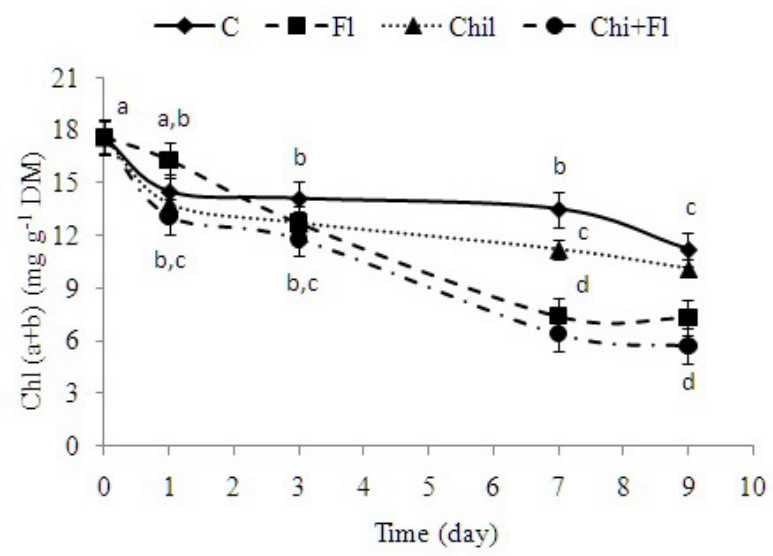

Fig. 6. Concentration of chlorophylls "a" and "b" $(\mathrm{Chl}(\mathrm{a}+\mathrm{b}))$ in the leaves of amaranth "Krepysh" grown under control conditions (C), night chilling up to $4 \pm 2^{\circ} \mathrm{C}$ (Chil), soil flooding (Fl), as well as under combined effect of soil hypoxia and night chilling $(\mathrm{Chil}+\mathrm{Fl})$. Bars indicate standard deviation $(\mathrm{n}=7)$ Other explanations as in Fig. 1.

experiment and it fell by 60,43 and $68 \%$, respectively, on the 9th day (Fig. 4). Similarly, the content of xantophylls and carotenoids $(\mathrm{C}(\mathrm{x}+\mathrm{c}))$ (Fig. 5) also changed.

The levels of all photosynthetic pigments deteriorated more due to the effects of soil hypoxia and a combination of both stress factors than due to night hypothermia (Figs 4 and 5).

Growth processes are an integral indicator of the physiological state of plants. As a result of the research, it was found that under the influence of each stress factor: soil flooding, night hypothermia, and their combination, the increase in the height of the plants did not exceed 25, 11 and $2 \%$, respectively over the 9 days of the experiment, while the control plants increased in stalk length by $68 \%$ (Fig. 6).

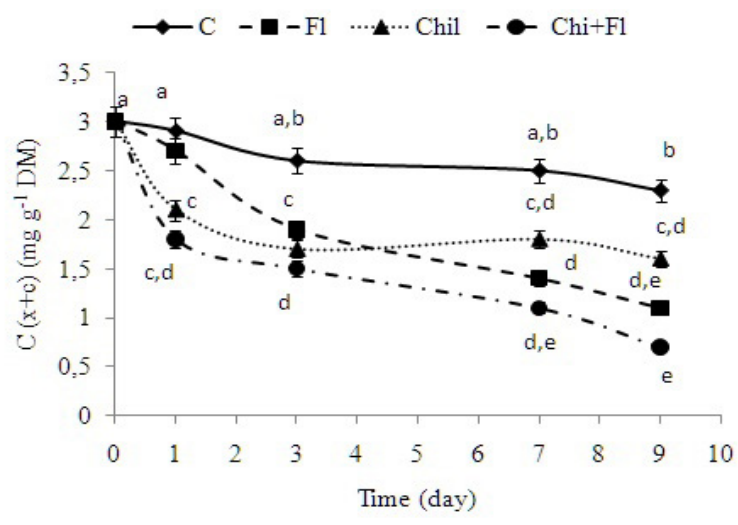

Fig. 7. Concentration of xantophylls and carotenoids $(\mathrm{C}(\mathrm{x}+\mathrm{c}))$ in the leaves of amaranth "Krepysh" growing under control conditions (C), the night chilling up to $4 \pm 2^{\circ} \mathrm{C}$ (Chil), soil flooding ( $\mathrm{Fl}$ ), as well as under combined effect of soil hypoxia and night chilling up (Chil $+\mathrm{Fl})$. Bars indicate standard deviation $(\mathrm{n}=7)$. Other explanations as in Fig. 1.

The dry mass of the aerial part of the control plants increased by $344 \%$ by the end of the experiment (Fig. 7). Under the influence of hypoxia, night hypothermia and their combination, the dry biomass of plants increased more slowly: by 188,93 and $33 \%$, respectively.

\section{CONCLUSIONS}

Amaranthus cruentus L. cv. "Krepysh" is thermophilic and drought-resistant but also sensitive to nighttime hypothermia and soil flooding. An analysis of the results obtained in the study of the influence of nighttime hypothermia, soil hypoxia and the combined activities of these stress factors on the adaptation potential of the plant showed the following:

The intensity of the peroxidative processes and superoxide dismutase activity changed in the antiphase relative to each other, both in the control and in the experimental plants.

1. Under the influence of nighttime hypothermia, unlike hypoxia, the content of amaranthine after a sharp decline at the beginning of the experiment then increased and significantly exceeded the control level up to the end of the experiment. It is assumed that cold induces the biosynthesis of amaranthine, whereas during the development of hypoxic stress in the reactions of reactive oxygen species neutralization, the constitutive amaranthine is used.

2 . The negative effect of hypothermia on the content of photosynthetic pigments, the growth process and biomass accumulation is more pronounced when combined with the effect of soil hypoxia, which may be associated with a decrease in the overall level of metabolism during hypothermia, and is one of the adaptive responses of plants.

3. With the combined activities of soil hypothermia and soil hypoxia on plants, the negative effects are greater than the combined effects of each stressor applied separately. 
Conflict of interest: The authors declare no conflict of interest.

\section{REFERENCES}

Amelyanchik O.A., Bolysheva T.N., Gomonova N.F., Durinina E.P., Egorov V.S., Egorova E.V., Edemsky N.L., Karpova E.A., Mineev V.G., Prizhukova V.G., and Sychev V.G., 2001. Workshop on agrochemistry. Study guide. (Ed. V.G. Mineev), P. 688, Moscow State University, Moscow, Russia.

Arbona V., Hossain Z., Lopez-Climent M.F., Prerez-Clemente R.M., and Gomez-Cadenas A., 2008. Antioxidant enzymatic activity is linked to waterlogging stress tolerance in citrus. Physiol. Plant., 132, 452-466.

https://doi.org/10.1111/j.1399-3054.2007.01029.x

Asada K., 2006. Production and scavenging of reactive oxygen species in chloroplasts and their functions. Plant. Physiol., 141, 391-396. https://doi.org/10.1104/pp.106.082040

Balakhnina T., Bennicelli R., Stępniewska Z., Stępniewski W., Borkowska A., and Fomina I.., 2012. Stress responses of spring rape plants to soil flooding. Int. Agrophys., 26, 347353. https://doi.org/10.2478/v10247-012-0049-z

Balakhnina T., Bennicelli R., Stępniewska Z., Stępniewski W., and Fomina I., 2010. Oxidative damage and antioxidant defense system in leaves of Vicia faba major L. cv. Bartom during soil flooding and subsequent drainage. Plant Soil, 327, 293-301. https://doi.org/10.1007/s11104-009-0054-6

Balakhnina T.I., Gavrilov A.B., Włodarczyk T.M., Borkowska A., Nosalewicz M., and Fomina I.R., 2009. Dihydroquercetin protects barley seeds against mould and increases seedling adaptive potential under soil flooding. Plant Growth Regul., 57, 127-135. https://doi.org/10.1007/s10725-008-9327-y

Bennicelli R.P., Stępniewski W., Zakrzhevsky D.A., Balakhnina T.I., Stępniewska Z., and Lipiec J., 1998. The effect of soil aeration on superoxide dismutase activity, malondialdehyde level, pigment content and stomatal diffusive resistance in maize seedlings. Environ. Exp. Bot., 203, 203-211. https://doi.org/10.1016/s0098-8472(97)00044-0

Clemente A.C. and Desai P.V., 2011. Evaluation of the hematological, hypoglycemic, hypolipidemic and antioxidant properties of Amaranthus tricolor leaf extract in rat. Trop. J. Pharm. Res., 10, 595-602. https://doi.org/10.4314/tjpr.v10i5.8

Foyer C.H. and Halliwell B., 1976. The presence of glutathione and glutathione reductase in chloroplasts: A proposed role in ascorbic acid metabolism. Planta, 13, 21-25. https://doi.org/10.1007/bf00386001

Gambarova N.G. and Gins M.S., 2008. Characteristics of oxidative stress of plants with $\mathrm{C} 3$ and $\mathrm{C} 4$ photosynthesis during salinization. Russ. Agric. Sci., 34, 77-80. https://doi.org/10.3103/s1068367408020031
Giannopolitis C.N. and Ries S.K., 1977. Superoxide dismutases. I. Occurrence in higher plants. Plant Physiol., 59, 309-314. https://doi.org/10.1104/pp.59.2.309

Gins M.S., Gins V.K., Motyleva S.M., Kulikov I.M., Medvedev S.M., Pivovarov V.F., and Mertvishcheva M.E., 2017. Metabolites with antioxidant and protective functions from leaves of vegetable amaranth (Amaranthus tricolor L.) (in Russian). Agric. Biol., 52, 1030-1040. https://doi.org/10.15389/agrobiology.2017.5.1030eng

Gins M.S., Gins V.K., Pivovarov V.F., and Kononkov P.F., 2016. Biologically active compounds with antioxidant activity in the amaranth red leaves' extract. Russ. Agric. Sci.,42,420-422.https://doi.org/10.3103/s1068367416060070

Gins V.K., Balakhnina T.I., Gins M.C., and Kononkov P.F., 1997. Influence of UV-A radiation on the intensity of processes of peroxide oxidation of membrane lipids and the system of protection against oxidative degradation in cotyledon leaves Amaranthus tricolor L. Materials of the II Int. Symp. "New and non-traditional plants and prospects for their use". NCBI RAS, Moscow-Pushchino, 1, 65-68.

Lichtenthaler H.K. and Wellburn A.R., 1985. Determination of total carotenoids and chlorophylls A and B of leaf in different solvents. Biol. Soc. Trans., 11, 591-592. https://doi.org/10.1042/bst0110591

Lukatkin A.S. and Golovanova V.S., 1988. Intensity of lipid peroxidation in chilled leaves of heat-loving plants. Physiol. Plants, 35, 773-780.

Phebe D., Chew M.K., Suraini A.A., Lai O.M., and Janna O.A., 2009. Red-fleshed pitaya (Hylocereus polyrhizus) fruit colour and betacyanin content depend on maturity. Food Res. Int., 16, 233-242.

Shao L., Liu G.L., Li Y.Y., and Peng C.L., 2009. Comparison of physiological characteristics in leaves of Amaranthus tricolor L. 'red flower' and 'green leaf' under high temperature (in Chinese). J. Tropical Subtropical Botany, 17, 378-382.

Stintzing F.C., Schieber A., and Carle R., 2002. Betacyanins in fruits from red-purple pitaya, Hylocereus polyrhizus (Weber). Britton \& Rose. Food Chemistry, 77, 101-106. https://doi.org/10.1016/s0308-8146(02)00168-1

Uchiyama M. and Mihara M., 1978. Determination of malonaldehyde precursor in tissues by thiobarbituric acid test. Anal. Biochem., 86, 287-297. https://doi.org/10.1016/0003-2697(78)90342-1

Xiong-Wei Chen, Ling Shao, Li-Ying Song, Yuan-Jun Chen, Chang-Lian Peng, and Qiang Zhang, 2013. Amaranthine plays an important role in photoprotection for Alternanthera sessilis under photooxidative stress. Biotechnol. Biotec. Eq., 27,3791-3797.https://doi.org/10.5504/bbeq.2013.0024

Zakrzhevsky D.A., Balakhnina T.I., Stępniewski W., Stępniewska S., Bennicelli R.P., and Lipiec J., 1995. Oxidation and growth processes in roots and leaves of higher plants at different oxygen availability in soil. Russ. J. Plant. Physiol., $42,242-248$. 